\title{
Article \\ High Hole Concentration and Diffusion Suppression of Heavily Mg-Doped p-GaN for Application in Enhanced-Mode GaN HEMT
}

\author{
Jin-Ji Dai ${ }^{1,2}$, Thi Thu Mai ${ }^{1}$, Ssu-Kuan Wu ${ }^{1}$, Jing-Rong Peng ${ }^{1}$, Cheng-Wei Liu ${ }^{1}$, Hua-Chiang Wen ${ }^{1}$, \\ Wu-Ching Chou ${ }^{1, *}$, Han-Chieh $\mathrm{Ho}^{2}$ and Wei-Fan Wang ${ }^{2}$
}

check for

updates

Citation: Dai, J.-J.; Mai, T.T.; Wu, S.-K.; Peng, J.-R.; Liu, C.-W.; Wen, H.-C.; Chou, W.-C.; Ho, H.-C.; Wang, W.-F. High Hole Concentration and Diffusion Suppression of Heavily Mg-Doped p-GaN for Application in Enhanced-Mode GaN HEMT.

Nanomaterials 2021, 11, 1766. https:// doi.org/10.3390/nano11071766

Academic Editor: Valentin Jmerik

Received: 8 May 2021

Accepted: 5 July 2021

Published: 7 July 2021

Publisher's Note: MDPI stays neutral with regard to jurisdictional claims in published maps and institutional affiliations.

Copyright: (c) 2021 by the authors. Licensee MDPI, Basel, Switzerland. This article is an open access article distributed under the terms and conditions of the Creative Commons Attribution (CC BY) license (https:/ / creativecommons.org/licenses/by/ $4.0 /)$.
1 Department of Electrophysics, National Yang Ming Chiao Tung University, Hsinchu 30010, Taiwan; jinjidai@gmail.com (J.-J.D.); maithucs@gmail.com (T.T.M.); wusykuann@gmail.com (S.-K.W.); sakura77988@gmail.com (J.-R.P.); william798424@gmail.com (C.-W.L.); a091316104@gmail.com (H.-C.W.)

2 Technology Development Division, Episil-Precision Inc., Hsinchu 30010, Taiwan; hanchiehho@epi.episil.com (H.-C.H.); warren.wang@epi.episil.com (W.-F.W.)

* Correspondence: wcchou957@nycu.edu.tw; Tel.: +886-3-5712121 (ext. 56129)

\begin{abstract}
The effect of $\mathrm{Mg}$ doping on the electrical and optical properties of the p-GaN/AlGaN structures on a Si substrate grown by metal organic chemical vapor deposition was investigated.

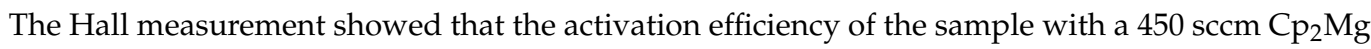
flow rate reached a maximum value of $2.22 \%$. No reversion of the hole concentration was observed due to the existence of stress in the designed sample structures. This is attributed to the higher $\mathrm{Mg}$-to-Ga incorporation rate resulting from the restriction of self-compensation under compressive strain. In addition, by using an AlN interlayer (IL) at the interface of $\mathrm{p}-\mathrm{GaN} / \mathrm{AlGaN}$, the activation rate can be further improved after the doping concentration reaches saturation, and the diffusion of $\mathrm{Mg}$ atoms can also be effectively suppressed. A high hole concentration of about $1.3 \times 10^{18} \mathrm{~cm}^{-3}$ can be achieved in the $\mathrm{p}-\mathrm{GaN} / \mathrm{AlN}-\mathrm{IL} / \mathrm{AlGaN}$ structure.
\end{abstract}

Keywords: GaN material; Mg doping; MOCVD; Hall measurement; PL spectroscopy

\section{Introduction}

The AlGaN/GaN high-electron mobility transistor (HEMT) on Si has received tremendous research attention in high-power device application due to its large breakdown electric field, high electron saturation velocity, and good thermal conductivity [1]. In order to guarantee a safe operation and simplify the circuit architecture, the AlGaN/GaN HEMT is made in the enhanced mode (E-mode) configuration of normally-off operation [2]. The most common and commercial E-mode HEMT is designed in the $\mathrm{p}-\mathrm{GaN} / \mathrm{AlGaN} / \mathrm{GaN}$ HEMT configuration. The $\mathrm{p}-\mathrm{GaN}$ raises the $\mathrm{GaN}$ conduction band of the AlGaN/GaN HEMT above the Fermi level, leading to the depletion of the two-dimensional electron gas (2DEG) channel at zero gate bias [3]. Therefore, an E-mode p-HEMT with a higher and stable threshold voltage (Vth) is expected by increasing the hole concentration. However, $\mathrm{Mg}$ doping for higher hole concentrations encountered several challenges, including (1) the compensation effect of the donor due to native defects $\left(\mathrm{V}_{\mathrm{N}}\right)$ and dislocations [4-6], (2) low p-type activation of $\mathrm{Mg}-\mathrm{H}$ into $\mathrm{GaN}[7,8]$, (3) self-compensation effect due to saturation Mg doping-induced donor-type defects [9-11], (4) the formation of pyramidal defects from Mg segregation on threading dislocation [12,13], and (5) Mg diffusion into the AlGaN barrier layer and GaN channel layer [14,15]. Although, L. Sang et al. recently showed that the hole concentration and activation efficiency of Mg-doped p-GaN grown on a freestanding GaN substrate of a low dislocation density could be improved dramatically [6]. Yingda Chen et al. discovered that the growth technique of indium surfactant-assisted delta doping could substantially enhance the hole concentration of a p-GaN/u-GaN homostructure grown on a 2-inch c-plane sapphire to $1.5 \times 10^{18} \mathrm{~cm}^{-3}$ [16]. However, the issue 
of low activation efficiency for Mg-doped p-GaN/AlGaN hetero-structures on the more economic $\mathrm{Si}$ substrates remains. As the $\mathrm{Mg}$ doping increases, the deep-level emission dominates in the photoluminescence (PL) and cathodoluminescence (CL) spectra $[17,18]$. This implies the formation of deeper donors to compensate holes or the creation of deeper $\mathrm{Mg}$ acceptor levels rather than shallow acceptor levels, further resulting in the difficulty to activate holes from the deep $\mathrm{Mg}$ acceptors to the valence band and decrease the activation efficiency. Therefore, it is essential to further investigate the effect of $\mathrm{Mg}$ doping on the electronic and optical properties to discover the optimized growth condition for better activation efficiency.

With the case of $\mathrm{Mg}$ diffusion into the AlGaN barrier layer and GaN channel layer, Loizos Efthymiou et al. discovered that Vth shifts firmly with Mg diffusion [19]. CL measurements revealed $\mathrm{Mg}$ diffusion along the dislocation [20]. Mg diffusion along the edgetype and mixed-type dislocations was also evidenced by transmission electron microscopy and atom probe tomography [21,22]. As a result, it is crucial to explore how to suppress $\mathrm{Mg}$ diffusion for better device performance of Mg-doped p-GaN/AlGaN/GaN HEMTs.

In the current work, the flow rate of $\mathrm{Cp}_{2} \mathrm{Mg}$ was modulated to grow Mg-doped $\mathrm{p}-\mathrm{GaN}$ on $\mathrm{AlGaN}$ to study the effect of different $\mathrm{Mg}$ doping concentrations on the hole concentration and activation efficiency. The PL experiment was carried out to investigate the deep emissions and self-compensation at various doped Mg levels. In addition, Hsien-Chin Chiu et al. demonstrated that a thin AlN etch stop layer in the p-GaN/AlN/AlGaN/GaN HEMT structure can effectively improve the device $\mathrm{R}_{\mathrm{ON}}$ uniformity and reduce the leakage current $[23,24]$. Thus, the influence of a thick GaN and thin AlN interlayer (IL) at the interface of the $\mathrm{Mg}$-doped $\mathrm{p}-\mathrm{GaN}$ and $\mathrm{AlGaN}$ layer on the activation efficiency and $\mathrm{Mg}$ diffusion was also investigated in this study.

\section{Materials and Methods}

The epitaxial structures of the Mg-doped GaN layers were grown by a metal organic chemical vapor deposition (MOCVD) system (Veeco Instruments Inc, Plainview, NY, USA) on 6-inch $\mathrm{Si}\left(\begin{array}{lll}1 & 1 & 1\end{array}\right)$ substrates, as shown in Figure 1. The conventional source precursors including trimethylaluminum (TMAl), trimethylgallium (TMGa), ammonia $\left(\mathrm{NH}_{3}\right)$, and bis(cyclopentadienyl) magnesium $\left(\mathrm{Cp}_{2} \mathrm{Mg}\right.$ ) were used to grow the $\mathrm{AlN}, \mathrm{AlGaN}, \mathrm{GaN}$, and Mg-doped p-GaN layers. To avoid Ga-Si melt-back etching, a $200 \mathrm{~nm}$ AlN nucleation layer was first grown at $1030^{\circ} \mathrm{C}$ on Si substrate. There are three types of samples, A, B, and C, as shown in Figure 1. All samples applied the same step-graded AlGaN buffers, consisting of a $200 \mathrm{~nm} \mathrm{Al}_{0.7} \mathrm{Ga}_{0.3} \mathrm{~N}$ layer, a $300 \mathrm{~nm} \mathrm{Al} \mathrm{N}_{0.5} \mathrm{Ga}_{0.5} \mathrm{~N}$ layer, and a $300 \mathrm{~nm} \mathrm{Al}{ }_{0.3} \mathrm{Ga}_{0.7} \mathrm{~N}$ layer grown at $1020^{\circ} \mathrm{C}$ to modulate stress for avoiding cracking. The sample structures were designed for high $\mathrm{Mg}$ activation rates and suppressing $\mathrm{Mg}$ diffusion into the under-layers. For sample A, the $1000 \mathrm{~nm}$-thick Mg-doped p-GaN layers were grown at $990^{\circ} \mathrm{C}$ with different $\mathrm{Cp}_{2} \mathrm{Mg}$ flow rates of $0,200,450,600,750$, and $900 \mathrm{sccm}$, labeled as $\mathrm{A}_{0}, \mathrm{~A}_{200}, \mathrm{~A}_{450}, \mathrm{~A}_{600}$, $A_{750}$, and $A_{900}$, respectively. For both samples $B$ and $C$, the $C p_{2} M g$ flow rate was $900 \mathrm{sccm}$ for investigating the effect of undoped $\mathrm{GaN}(\mathrm{u}-\mathrm{GaN})$ and $\mathrm{AlN}-\mathrm{IL}$ on the $\mathrm{Mg}$ activation rate and diffusion. The post-growth thermal activation of Mg-doped $\mathrm{p}-\mathrm{GaN}$ was performed for $20 \mathrm{~min}$ at $720^{\circ} \mathrm{C}$ under a nitrogen atmosphere. The secondary ion mass spectroscopy (SIMS) measurement was carried out on all samples to determine the $\mathrm{Mg}$ concentration in the p-GaN layer by the IMS-6f (CAMECA SAS, Gennevilliers, France). In order to investigate the electrical properties of $\mathrm{p}-\mathrm{GaN}$, the standard Hall effect with the Van der Pauw method was conducted at room temperature by the HMS-3000 (Ecopia Corporation, Anyang-City, South Korea). The optical properties of all samples were studied using low-temperature photoluminescence (PL) spectroscopy by the excitation of a HeCd laser at $325 \mathrm{~nm}$. The threading dislocation density (TDD) was evaluated from the full width at half maximum (FWHM), scanned on GaN (002) and (102) planes by X-ray diffraction (XRD, X'Pert Pro MRD, Malvern Panalytical, Almelo, The Netherlands). The characterization of structure strain was performed by Raman scattering. The effect of the $\mathrm{Mg}$ doping concentration on the surface morphology was carried out by scanning electron microscopy (SEM, JSM7001F, 
JEOL, Tokyo, Japan), optical microscopy (OM, AL100, Olympus Corporation, Tokyo, Japan), and atomic force microscopy (AFM, NT-MDT Spectrum Instruments, Moscow, Russia).

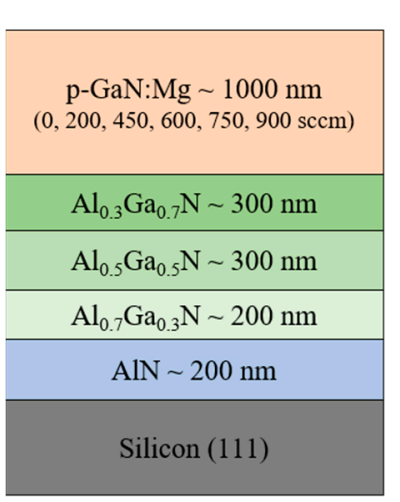

(a)

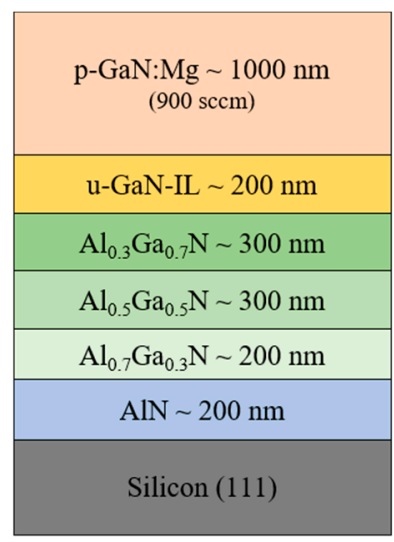

(b)

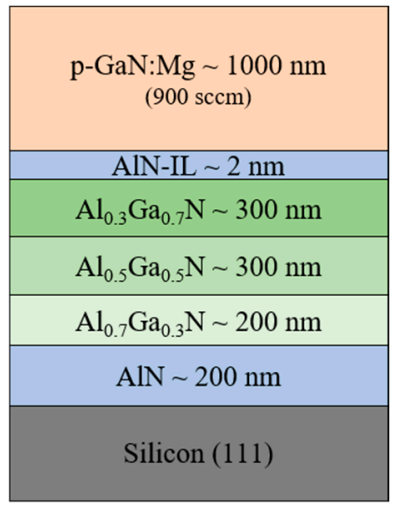

(c)

Figure 1. Schematic structures of $\mathrm{p}-\mathrm{GaN}$ samples: (a) sample A with varying $C \mathrm{p}_{2} \mathrm{Mg}$ flow rates (0, 200, 450, 600, 750, $900 \mathrm{sccm}$ ), (b) sample B with $\mathrm{Cp}_{2} \mathrm{Mg} 900 \mathrm{sccm}$ and an additional $200 \mathrm{~nm}$ undoped GaN interlayer, and (c) sample $\mathrm{C}$ with $\mathrm{Cp}_{2} \mathrm{Mg} 900 \mathrm{sccm}$ and a $2 \mathrm{~nm}$ AlN interlayer.

\section{Results and Discussion}

The hole carrier concentration and activation efficiency as a function of $\mathrm{Mg}$ doping are revealed in Table 1 and Figure 2. As we can see, the hole concentration increases, corresponding to decreased mobility with the increasing Mg doping. Meanwhile, the resistivity decreases initially and then increases with the Mg doping. The activation efficiency (Mg doping efficiency), which is defined as the ratio of the hole concentration (obtained from Hall measurement) and Mg doping density (measured by SIMS), increases initially and reaches a maximum value of $2.22 \%$ at Mg doping of $2.42 \times 10^{19} / \mathrm{cm}^{3}(450 \mathrm{sccm})$, and then it decreases with the Mg doping. This can be attributed to the Mg saturated concentration of about $2 \times 10^{19} / \mathrm{cm}^{3}$. Furthermore, the low $\mathrm{Mg}$ concentration behavior presented in our samples is similar to that of other reported data [11,25] for a GaN:Mg hetero-epitaxial layer on a sapphire substrate, as shown in Figure 2. However, they all showed constant reversion of the hole concentration after Mg saturation, owing to the self-compensation effect. Even A. Klump et al. applied UV illumination to reduce $\mathrm{H}$ passivation and the self-compensation impact on the GaN:Mg films, which was just helpful on the concentration below the $\mathrm{Mg}$ saturation. In our case, when the $\mathrm{Mg}$ doping is more than the self-compensation onset of $2.42 \times 10^{19} / \mathrm{cm}^{3}(450 \mathrm{sccm})$, it is worth noting that the activated hole concentrations still rise without a hole concentration reversion. However, the decrease in activation efficiency could be ascribed to the starting existence of high $\mathrm{Mg}$ doping-induced defects, for example, the formation of $\mathrm{Mg}$ interstitials [9,17], nitrogen vacancy $\mathrm{V}_{\mathrm{N}}[9,26], \mathrm{Mg}_{\mathrm{Ga}}-\mathrm{V}_{\mathrm{N}}$ complexes [11,27], and pyramidal inversion domain (PID) defects $[28,29]$. Another scenario could be the building possibility of Mg-N-Mg clusters. The rising formation probability of $\mathrm{Mg}-\mathrm{N}-\mathrm{Mg}$ double acceptors could split the acceptor level and create deeper acceptor states and further decrease the density of a single $\mathrm{Mg}$ shallow acceptor. The deeper acceptor states are not active in creating free holes, leading to lower activation efficiency. For even higher $\mathrm{Mg}$ doping concentrations, the possibility to generate $\mathrm{Mg}_{3} \mathrm{~N}_{2}$ clusters increases [30,31]. The formation of $\mathrm{Mg}_{3} \mathrm{~N}_{2}$ clusters decreases the single $\mathrm{Mg}$ concentration, and the energy states of $\mathrm{Mg}_{3} \mathrm{~N}_{2}$ clusters are deep levels in the energy gap and do not contribute free holes. With a consistent result, we also obtained precipitation of Mg-rich and pyramid-shaped defects on our SEM and optical microscope images, respectively, after the flow rate of $450 \mathrm{sccm}$ (not shown here). The energy-dispersive X-ray spectroscopy (EDS) analysis also exhibited the Mg content of the $900 \mathrm{sccm}$ sample, about $2.4 \%$ on the Mg-rich precipitates and around three times that of the blank background $(0.79 \%)$. In addition, AFM images show the root mean square (RMS) of 
the surface roughness increases from 0.49 to $1.75 \mathrm{~nm}$ in the $5 \mu \mathrm{m} \times 5 \mu \mathrm{m}$ scan area, while the $\mathrm{Mg}$ flow rate increases from 0 to $900 \mathrm{sccm}$.

Table 1. Dependence of activation efficiency and electrical properties on the $\mathrm{Cp}_{2} \mathrm{Mg}$ flow rates.

\begin{tabular}{|c|c|c|c|c|c|c|}
\hline Structure & $\begin{array}{c}\mathrm{Cp}_{2} \mathrm{Mg} \text { Source } \\
(\mathrm{sccm})\end{array}$ & $\begin{array}{l}\text { Mg Doping } \\
\text { Concentration } \\
\quad\left(\mathrm{cm}^{-3}\right)\end{array}$ & $\begin{array}{c}\text { Hole } \\
\text { Concentration } \\
\left(\mathrm{cm}^{-3}\right)\end{array}$ & $\begin{array}{l}\text { Mobility } \\
\left(\mathrm{cm}^{2} / \mathrm{V}-\mathrm{s}\right)\end{array}$ & $\begin{array}{l}\text { Resistivity } \\
\text { (ohm-cm) }\end{array}$ & $\begin{array}{c}\text { Activation } \\
\text { Efficiency } \\
(\%)\end{array}$ \\
\hline \multirow{5}{*}{$\mathrm{p}-\mathrm{GaN} / \mathrm{Al}_{0.3} \mathrm{Ga}_{0.7} \mathrm{~N}$} & 200 & $1.20 \times 10^{19}$ & $(1.25 \pm 0.06) \times 10^{17}$ & $27.54 \pm 1.38$ & $1.87 \pm 0.09$ & 1.04 \\
\hline & 450 & $2.42 \times 10^{19}$ & $(5.38 \pm 0.27) \times 10^{17}$ & $7.69 \pm 0.38$ & $1.51 \pm 0.08$ & 2.22 \\
\hline & 600 & $3.75 \times 10^{19}$ & $(7.49 \pm 0.37) \times 10^{17}$ & $5.63 \pm 0.28$ & $1.48 \pm 0.07$ & 2.00 \\
\hline & 750 & $4.87 \times 10^{19}$ & $(7.95 \pm 0.40) \times 10^{17}$ & $4.51 \pm 0.23$ & $1.74 \pm 0.09$ & 1.63 \\
\hline & 900 & $6.05 \times 10^{19}$ & $(8.71 \pm 0.44) \times 10^{17}$ & $3.54 \pm 0.18$ & $2.02 \pm 0.10$ & 1.44 \\
\hline
\end{tabular}

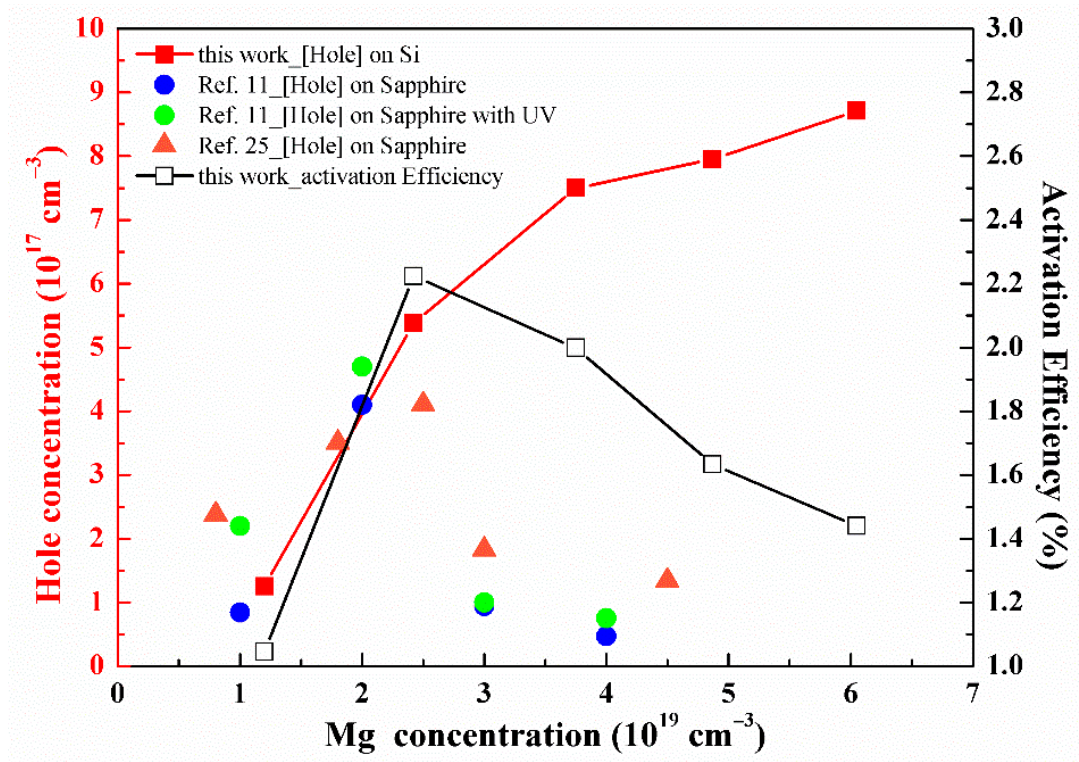

Figure 2. The hole concentration (red solid squares) and activation efficiency (open squares) of $\mathrm{p}-\mathrm{GaN}: \mathrm{Mg}$ layer as a function of the $\mathrm{Mg}$ doping concentration. The results from references [11,25] are also plotted for comparison, as shown by blue circles, green circles, and orange triangles.

The PL spectra of $\mathrm{p}-\mathrm{GaN}$ films at $10 \mathrm{~K}$ with different $\mathrm{Mg}$ doping concentrations are shown in Figure 3. The PL of the undoped GaN film shows a sharp near-band edge emission (NBE) at $3.46 \mathrm{eV}(358.4 \mathrm{~nm})$, as shown in Figure 3a. The broad emissions below $3.2 \mathrm{eV}$ are attributed to the defect emissions from the AlGaN layers. In addition, the oscillation in the PL intensity below $3.2 \mathrm{eV}$ is due to the Fabry-Perot interference of the whole sample structure. By measuring the energy separation of the two nearest peaks $\Delta \mathrm{E}$, the total sample thickness could be evaluated by $\mathrm{d}=\mathrm{hc} /(2 \mathrm{n} \Delta \mathrm{E}) \approx 2 \mu \mathrm{m}$, where $\mathrm{h}, \mathrm{c}$, and $\mathrm{n}$ are the Planck constant, speed of light, and refraction index at the emission peak, respectively. When the $\mathrm{Mg}$ doping is turned on at $200 \mathrm{sccm}$, the native donor $\left(\mathrm{V}_{\mathrm{N}}\right)[4]$ and shallow Mg acceptor pair (DAP) emission dominates the PL spectrum, as it can be seen in Figure 3b. The peak of DAP is around $3.1 \mathrm{eV}$. As the Mg doping is further increased to $450 \mathrm{sccm}$, the peak energy of blue luminescence (BL) is near 2.8 to $3.0 \mathrm{eV}$ (Figure 3c). The emission peak near 2.8-3.0 eV was attributed to the deep donor-to-shallow acceptor transition [32,33]. These deep donors could be created by the heavy Mg doping-induced defects. The emission peak near 2.8-3.2 eV could also be ascribed to the recombination of a native donor and heavy $\mathrm{Mg}$ doping-induced deep $\mathrm{Mg}$ acceptor. The PL spectra presented in Figure 3d-f, for higher Mg doping samples, are basically the same as in Figure 3c. The peak intensity of green luminescence (GL) and yellow luminescence (YL) becomes more prominent with increased $\mathrm{Mg}$ doping, which means that structural defects related 
to $V_{N}$ begin to increase [26,34]. In general, the collected PL data corroborate the results of electrical measurements mentioned above (Table 1 and Figure 2). As the Mg doping exceeds $450 \mathrm{sccm}$, the more $\mathrm{Mg}$ atoms incorporated into the GaN crystal generate not only more single $\mathrm{Mg}$ shallow acceptors but also more $\mathrm{Mg}-\mathrm{N}-\mathrm{Mg}$ deep acceptors, or donor-type defects, leading to a drop-off in activation efficiency. If the BL emission at 2.8-3.0 eV of Figure $3 \mathrm{c}$ is due to the donor-to-deep acceptor recombination, the deep acceptors are about 300 to $500 \mathrm{meV}$ above the valence band compared with the activation energy of the shallow acceptor of about $200 \mathrm{meV}[35,36]$. Therefore, the deep acceptors have lower efficiency to be activated to offer free holes in the valence band for conducting. Similar competition of two emissions was also discovered recently by Hanxiao Liu et al. for their low- and high-Mg doping samples [18]. They attributed the two emissions at $3.25 \mathrm{eV}$ and $2.9 \mathrm{eV}$ to the shallow donor-to-acceptor and deep donor-to-acceptor transitions, respectively. We suggest that the BL near $2.9 \mathrm{eV}$ can be caused by both the deep acceptors and deep donors. The deep acceptors should result from the $\mathrm{Mg}$-rich and $\mathrm{Mg}_{3} \mathrm{~N}_{2}$ precipitates to decrease the activation efficiency. The deep donors of donor-like defects from the $V_{N}$ and $M g-V_{N}$ complexes can decrease the hole concentration by the self-compensation effect.

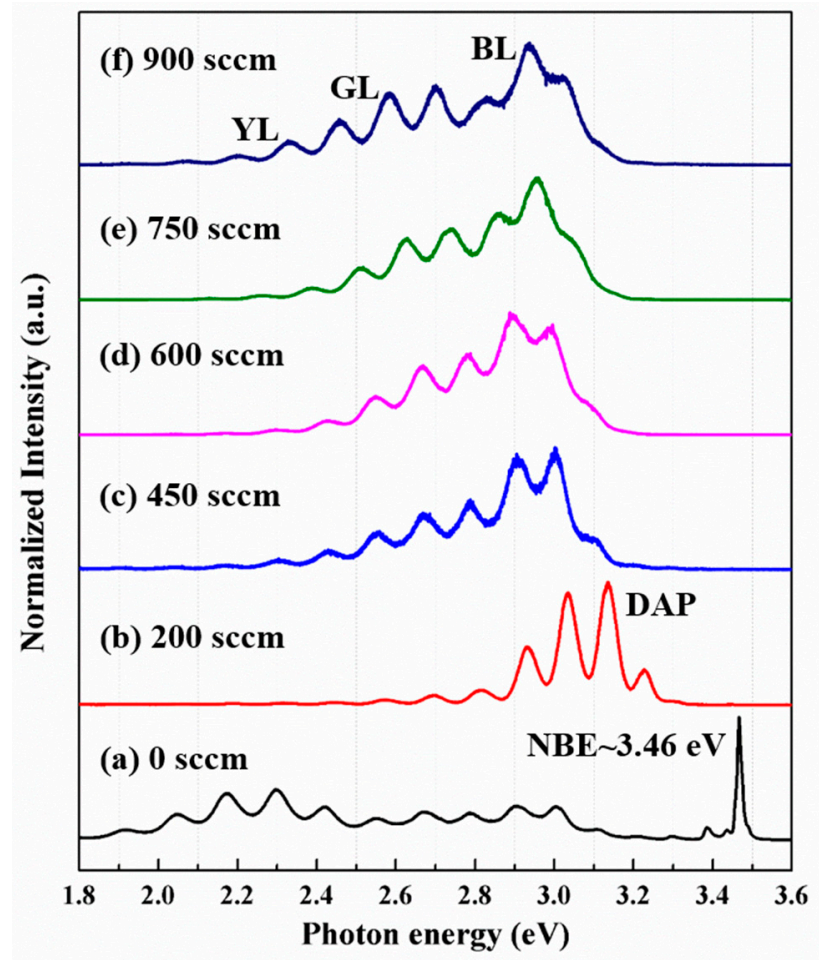

Figure 3. The low-temperature (10 K) PL spectra of $\mathrm{p}-\mathrm{GaN} / \mathrm{AlGaN}$ structures with varying $\mathrm{Cp}_{2} \mathrm{Mg}$ flow rates.

In order to investigate the effect of $\mathrm{Mg}$ diffusion on the activation efficiency, the electrical properties of samples $B$ and $C$ are discussed. Figure 4a shows the SIMS of samples $\mathrm{A}_{900}, \mathrm{~B}$, and $\mathrm{C}$. Mg diffusion is the strongest for sample B, the p-GaN homo-epitaxy of the $200 \mathrm{~nm} \mathrm{GaN}$ template. The difference in $\mathrm{Mg}$ diffusion for samples $\mathrm{A}_{900}$ and $\mathrm{C}$ is not significant. However, the hole concentration and activation efficiency are very different for three samples, as shown in Figure $4 \mathrm{~b}$. Suppose that the hole concentration evaluated by the Hall measurement is majorly contributed by the top part of the p-GaN layers; the similar $\mathrm{Mg}$ doping concentrations at the top of the $\mathrm{p}-\mathrm{GaN}$ layers for all three samples imply that the self-compensation effects are different. We would like to emphasize that the activation efficiency was effectively increased by decreasing the self-compensation effect, while the decrease in $\mathrm{Mg}$ diffusion was trivial, as extracted from the SIMS results. The p-GaN film grown on AlN-IL $(2 \mathrm{~nm}) / \mathrm{Al}_{0.3} \mathrm{Ga}_{0.7} \mathrm{~N}$ has the best activation efficiency of $2.2 \%$. In the event of $\mathrm{p}-\mathrm{GaN}$ grown on $\mathrm{Al}_{0.3} \mathrm{Ga}_{0.7} \mathrm{~N}$ and $\mathrm{GaN}$, the activation efficiencies are $1.4 \%$ and $0.8 \%$, 
respectively. This could be due to the strain between the layers to suppress the formation of the $\mathrm{Mg}$ doping-induced donor-type defects. These results indicate that aluminum has a smaller atomic radius than gallium, which can inhibit $\mathrm{Mg}$ diffusion and increase the compressive stress on the GaN:Mg film [37]. It is expected that a high $\mathrm{Al}$ composition could significantly suppress the self-compensation effect, reduce the Mg diffusion concentration, and further increase the hole concentration and activation rate.

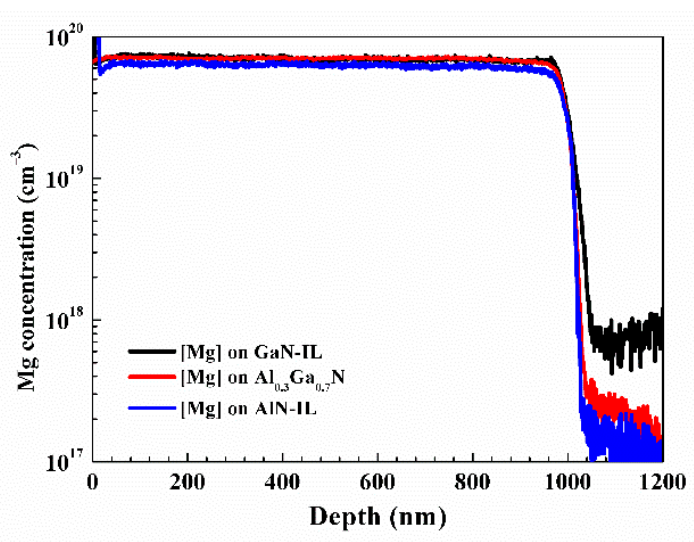

(a)

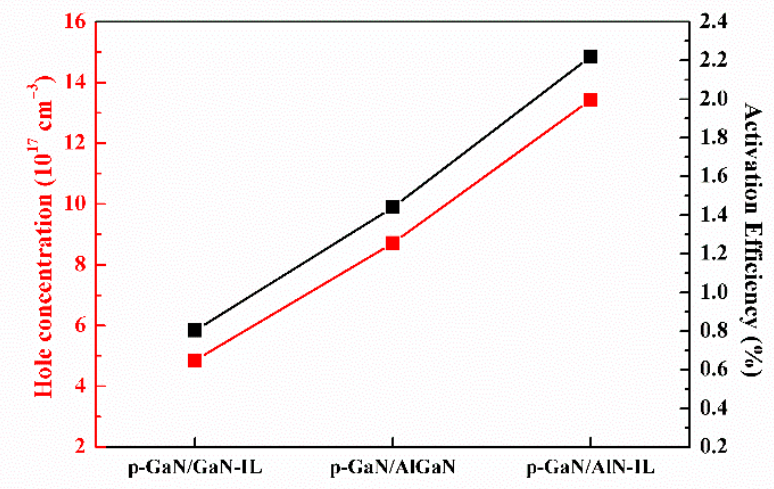

(b)

Figure 4. (a) Mg concentration profile measured by SIMS for three different structures. (b) The hole concentration (red squares) and activation efficiency (black squares) of Mg-doped p-GaN layers grown on GaN-IL, AlGaN, and AlN-IL under-layers.

Many research groups also investigated the role of stable and metastable $\mathrm{Mg}-\mathrm{H}$ complexes on the activation efficiency $[7,8,25]$. They discovered that the hole concentration is proportional to the density of $\mathrm{H}$ atoms from the $\mathrm{Mg}-\mathrm{H}$ complex measured by SIMS before thermal annealing. The $\mathrm{Mg}$ atoms without the formation of the $\mathrm{Mg}-\mathrm{H}$ complex could occupy the interstitials, $\mathrm{Mg}-\mathrm{V}_{\mathrm{N}}$ complexes, or lattice positions of nitrogen $\left(\mathrm{Mg}_{\mathrm{N}}\right)$. They are donor-type defects and play the role of self-compensation. As shown in Figure 5a, a higher $\mathrm{H}$ concentration was observed before annealing in $\mathrm{p}-\mathrm{GaN} / \mathrm{AlGaN}$ and $\mathrm{p}-\mathrm{GaN} / \mathrm{AlN}-$ IL structures than that in the p-GaN/GaN-IL structure. However, the p-GaN/AlN-IL structure displayed a similar $\mathrm{H}$ concentration to $\mathrm{p}-\mathrm{GaN} / \mathrm{AlGaN}$, which could not expound the higher hole concentration and activation efficiency with AlN-IL. Therefore, these two structures were measured by the HRXRD rocking curves for the FWHM of GaN (002) and (102) planes to calculate the threading dislocation densities (TDDs) [38]. The GaN $(002) /(102)$ planes of $678 / 1024$ arcsecs without AlN-IL, respectively, correspond to the screw/edge-type TDDs of $9.24 \times 10^{8}$ and $3.13 \times 10^{9} \mathrm{~cm}^{-2}$. The screw/edge-type TDDs of $7.98 \times 10^{8}$ and $3.51 \times 10^{9} \mathrm{~cm}^{-2}$ with the AlN-IL structure were calculated by the GaN $(002) /(102)$ planes of $630 / 1028$ arcsecs. In contrast to the relationship, the total TDDs with AlN-IL slightly increased from $4.05 \times 10^{9}$ to $4.30 \times 10^{9} \mathrm{~cm}^{-2}$, indicating that the TDDs do not dominate the hole concentration in this case. We recommend excluding the effect of $\mathrm{Mg}-\mathrm{H}$ and TDDs on the increasing activation efficiency after the Mg doping concentration reaches saturation. Furthermore, in Figure 5b, the PL spectra of p-GaN exhibit that the photon intensities of BL, GL, and YL decreased dramatically with AlN-IL. The lower concentration of self-compensation defects in the p-GaN on AlN-IL could be due to the greater compressive strain in $\mathrm{p}-\mathrm{GaN}$. This is consistent with our Raman spectra, where GaN E 2 (High) and A1 (LO) shift from 563.46 to $563.74 \mathrm{~cm}^{-1}$ and 722.26 to $726.19 \mathrm{~cm}^{-1}$, respectively. The Raman energy blue shift implies greater compressive stress in the $\mathrm{p}-\mathrm{GaN}$ epilayer with AlN-IL [39,40]. This effect is in agreement with the suppression of donorlike defects under greater compressive strains from inserting an AlN interlayer into the $\mathrm{Mg}$-doped $\mathrm{GaN} / \mathrm{AlGaN}$ superlattice by Hu et al. [41,42]. Herein, we would like to express that the existence of the greater compressive stress of heavily Mg-doped $\mathrm{GaN}$ is crucial in affecting the self-compensation effect because it can effectively extend the Fermi energy 
and consequently increase the formation energy of self-compensation defects [9]. This was mentioned in other research $[10,43,44]$ which found that a strain state from compressive to tensile is accompanied by the BL emission due to large local lattice relaxations by the generation of self-compensation defects. This study reveals that a high-Al composition layer under the $\mathrm{p}-\mathrm{GaN}$ layer can effectively enhance the hole concentration and significantly reduce the self-compensation effect. Furthermore, no reversion of the hole concentration could be observed after Mg saturation. This finding is precious for application in E-mode GaN HEMTs.

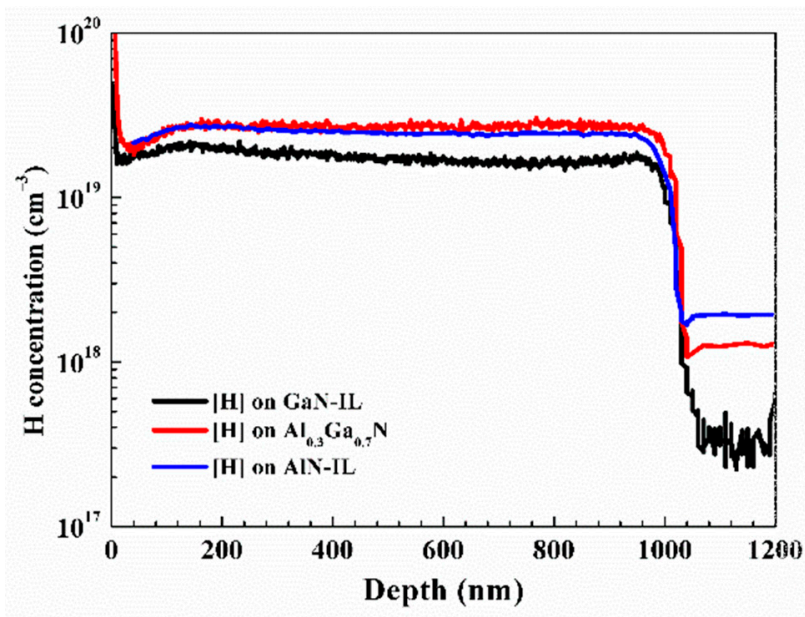

(a)

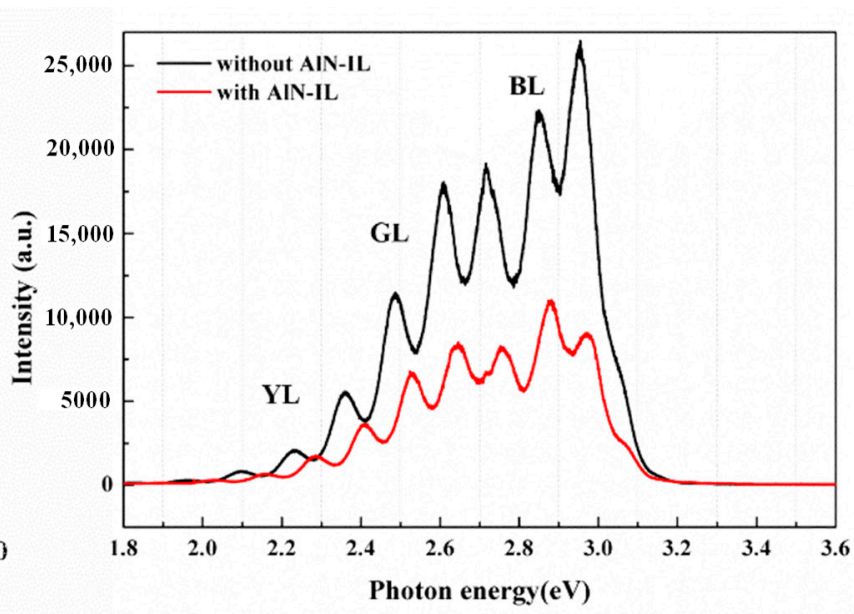

(b)

Figure 5. (a) The dependence of hydrogen concentration on depth investigated by SIMS. Black, red, and blue lines are results for $\mathrm{p}-\mathrm{GaN}$ on $\mathrm{GaN}-\mathrm{IL}, \mathrm{Al}_{0.3} \mathrm{Ga}_{0.7} \mathrm{~N}$, and $\mathrm{AlN}-\mathrm{IL}$ structures, respectively. (b) The low-temperature (10 K) PL spectra of $\mathrm{p}-\mathrm{GaN}$ with and without AlN-IL.

\section{Conclusions}

In this study, the flow rate of $\mathrm{Cp}_{2} \mathrm{Mg}$ was modulated to grow heavily $\mathrm{Mg}$-doped $\mathrm{p}-\mathrm{GaN}$ on $\mathrm{AlGaN}$ for application in enhanced-mode HEMTs. A maximum activation rate of $2.22 \%$ was accomplished with $\mathrm{Mg}$ doping of around $2.42 \times 10^{19} \mathrm{~cm}^{-3}$. The further increase in the hole concentration with the increasing $\mathrm{Mg}$ concentration reveals that the hole reversion could be restrained, owing to the decreased compensation-type defects resulting from the enhanced compressive strain. In addition, a high hole concentration of $1.3 \times 10^{18} \mathrm{~cm}^{-3}$ with a high activation efficiency was also achieved by heavy $\mathrm{Mg}$ doping of around $6.05 \times 10^{19} \mathrm{~cm}^{-3}$ in the $\mathrm{p}-\mathrm{GaN} / \mathrm{AlN}-\mathrm{IL} / \mathrm{AlGaN}$ structure. The diffusion of $\mathrm{Mg}$ can be effectively suppressed by inserting an AlN layer at the interface of Mg-GaN and AlGaN . The current results provide important information for the growth of $\mathrm{Mg}$-doped $\mathrm{p}-\mathrm{GaN}$ of a high hole concentration in E-mode HEMT application.

Author Contributions: J.-J.D. conceived and designed the sample structure and experiments, performed the epitaxial growth, and wrote the manuscript. H.-C.H. and W.-F.W. supported the epitaxial growth. T.T.M., S.-K.W., J.-R.P., C.-W.L. and H.-C.W. supported structural, optical, and electrical characterizations. W.-C.C. is the advisor who supervised the experiments. All authors contributed to discussing the results and comments on the manuscript. All authors have read and agreed to the published version of the manuscript.

Funding: This research was funded by the Ministry of Science and Technology, Taiwan, under grant No. MOST 109-2124-M-009-002-MY3.

Data Availability Statement: Data are contained within the article.

Conflicts of Interest: The authors declare no conflict of interest. 


\section{References}

1. Chen, K.J.; Haberlen, O.; Lidow, A.; Tsai, C.L.; Ueda, T.; Uemoto, Y.; Wu, Y. GaN-on-Si Power Technology: Devices and Applications. IEEE Trans. Electron. Devices 2017, 64, 779-795. [CrossRef]

2. Chen, K.J.; Zhou, C. Enhancement-mode AlGaN/GaN HEMT and MIS-HEMT technology. Phys. Status Solidi (a) 2010, 208, 434-438. [CrossRef]

3. Roccaforte, F.; Greco, G.; Fiorenza, P.; Iucolano, F. An Overview of Normally-Off GaN-Based High Electron Mobility Transistors. Materials 2019, 12, 1599. [CrossRef]

4. Buckeridge, J.; Catlow, C.R.A.; Scanlon, D.O.; Keal, T.; Sherwood, P.; Miskufova, M.; Walsh, A.; Woodley, S.M.; Sokol, A. Determination of the Nitrogen Vacancy as a Shallow Compensating Center in GaN Doped with Divalent Metals. Phys. Rev. Lett. 2015, 114, 016405. [CrossRef] [PubMed]

5. Sarkar, B.; Mita, S.; Reddy, P.; Klump, A.; Kaess, F.; Tweedie, J.; Bryan, I.; Bryan, Z.; Kirste, R.; Kohn, E.; et al. High free carrier concentration in p-GaN grown on AlN substrates. Appl. Phys. Lett. 2017, 111, 032109. [CrossRef]

6. Sang, L.; Ren, B.; Endo, R.; Masuda, T.; Yasufuku, H.; Liao, M.; Nabatame, T.; Sumiya, M.; Koide, Y. Boosting the doping efficiency of $\mathrm{Mg}$ in p-GaN grown on the free-standing GaN substrates. Appl. Phys. Lett. 2019, 115, 172103. [CrossRef]

7. Castiglia, A.; Carlin, J.-F.; Grandjean, N.R. Role of stable and metastable Mg-H complexes in p-type GaN for cw blue laser diodes. Appl. Phys. Lett. 2011, 98, 213505. [CrossRef]

8. Wide range doping control and defect characterization of GaN layers with various $\mathrm{Mg}$ concentrations. J. Appl. Phys. 2018, 124, 165706. [CrossRef]

9. Miceli, G.; Pasquarello, A. Self-compensation due to point defects in Mg-doped GaN. Phys. Rev. B 2016, 93, 93. [CrossRef]

10. Kirste, R.; Hoffmann, M.P.; Tweedie, J.; Bryan, Z.; Callsen, G.; Kure, T.; Nenstiel, C.; Wagner, M.R.; Collazo, R.; Hoffmann, A.; et al. Compensation effects in GaN:Mg probed by Raman spectroscopy and photoluminescence measurements. J. Appl. Phys. 2013, 113, 103504. [CrossRef]

11. Klump, A.; Hoffmann, M.P.; Kaess, F.; Tweedie, J.; Reddy, P.; Kirste, R.; Sitar, Z.; Collazo, R. Control of passivation and compensation in Mg-doped GaN by defect quasi Fermi level control. J. Appl. Phys. 2020, 127, 045702. [CrossRef]

12. Figge, S.; Kröger, R.; Böttcher, T.; Ryder, P.L.; Hommel, D. Magnesium segregation and the formation of pyramidal defects in p-GaN. Appl. Phys. Lett. 2002, 81, 4748-4750. [CrossRef]

13. Duguay, S.; Echeverri, A.; Castro, C.; Latry, O. Evidence of Mg Segregation to Threading Dislocation in Normally-Off GaN-HEMT. IEEE Trans. Nanotechnol. 2019, 18, 995-998. [CrossRef]

14. Posthuma, N.; You, S.; Liang, H.; Ronchi, N.; Kang, X.; Wellekens, D.; Saripalli, Y.; Decoutere, S. Impact of Mg out-diffusion and activation on the $\mathrm{p}-\mathrm{GaN}$ gate HEMT device performance. In Proceedings of the 2016 28th International Symposium on Power Semiconductor Devices and ICs (ISPSD), Prague, Czech Republic, 12-16 June 2016; pp. 95-98.

15. He, J.; Tang, G.; Chen, K.J. VTH Instability of p-GaN Gate HEMTs under Static and Dynamic Gate Stress. IEEE Electron. Device Lett. 2018, 39, 1. [CrossRef]

16. Chen, Y.; Wu, H.; Yue, G.; Chen, Z.; Zheng, Z.; Wu, Z.; Wang, G.; Jiang, H. Enhanced Mg Doping Efficiency in P-Type GaN by Indium-Surfactant-Assisted Delta Doping Method. Appl. Phys. Express 2013, 6, 041001. [CrossRef]

17. Nayak, S.; Gupta, M.; Waghmare, U.V.; Shivaprasad, S. Origin of Blue Luminescence in Mg -Doped GaN. Phys. Rev. Appl. 2019, 11, 014027. [CrossRef]

18. Liu, H.; Fu, H.; Fu, K.; Alugubelli, S.R.; Su, P.-Y.; Zhao, Y.; Ponce, F.A. Non-uniform Mg distribution in GaN epilayers grown on mesa structures for applications in GaN power electronics. Appl. Phys. Lett. 2019, 114, 082102. [CrossRef]

19. Efthymiou, L.; Murukesan, K.; Longobardi, G.; Udrea, F.; Shibib, A.; Terrill, K. Understanding the Threshold Voltage Instability During OFF-State Stress in p-GaN HEMTs. IEEE Electron. Device Lett. 2019, 40, 1253-1256. [CrossRef]

20. Chen, J.; Yi, W.; Kimura, T.; Takashima, S.; Edo, M.; Sekiguchi, T. Cathodoluminescene study of Mg implanted GaN: The impact of dislocation on Mg diffusion. Appl. Phys. Express 2019, 12, 051010. [CrossRef]

21. Usami, S.; Mayama, N.; Toda, K.; Tanaka, A.; Deki, M.; Nitta, S.; Honda, Y.; Amano, H. Direct evidence of Mg diffusion through threading mixed dislocations in GaN p-n diodes and its effect on reverse leakage current. Appl. Phys. Lett. 2019, $114,232105$. [CrossRef]

22. Yi, W.; Kumar, A.; Uzuhashi, J.; Kimura, T.; Tanaka, R.; Takashima, S.; Edo, M.; Yao, Y.; Ishikawa, Y.; Chen, J.; et al. Mg diffusion and activation along threading dislocations in GaN. Appl. Phys. Lett. 2020, 116, 242103. [CrossRef]

23. Chiu, H.-C.; Chang, Y.-S.; Li, B.-H.; Wang, H.-C.; Kao, H.-L.; Hu, C.-W.; Xuan, R. High-Performance Normally Off p-GaN Gate HEMT With Composite AlN/Al0.17Ga0.83N/Al0.3Ga0.7N Barrier Layers Design. IEEE J. Electron. Devices Soc. 2018, 6, 201-206. [CrossRef]

24. Chiu, H.-C.; Chang, Y.-S.; Li, B.-H.; Wang, H.-C.; Kao, H.-L.; Chien, F.-T.; Hu, C.-W.; Xuan, R. High Uniformity Normally-OFF p-GaN Gate HEMT Using Self-Terminated Digital Etching Technique. IEEE Trans. Electron. Devices 2018, 65, 4820-4825. [CrossRef]

25. Qi, H.; Zhang, S.; Liu, S.; Liang, F.; Yi, L.; Huang, J.; Zhou, M.; He, Z.; Zhao, D.; Jiang, D. The self-compensation effect of heavily Mg doped p-GaN films studied by SIMS and photoluminescence. Superlattices Microstruct. 2019, 133, 106177. [CrossRef]

26. Yan, Q.; Janotti, A.; Scheffler, M.; Van De Walle, C.G. Role of nitrogen vacancies in the luminescence of Mg-doped GaN. Appl. Phys. Lett. 2012, 100, 142110. [CrossRef]

27. Reshchikov, M.A.; Demchenko, D.O.; McNamara, J.D.; Fernández-Garrido, S.; Calarco, R. Green luminescence in Mg-doped GaN. Phys. Rev. B 2014, 90, 90. [CrossRef] 
28. Remmele, T.; Albrecht, M.; Irmscher, K.; Fornari, R.; Straßburg, M. Pyramidal inversion domain boundaries revisited. Appl. Phys. Lett. 2011, 99, 141913. [CrossRef]

29. Iwata, K.; Narita, T.; Nagao, M.; Tomita, K.; Kataoka, K.; Kachi, T.; Ikarashi, N. Atomic resolution structural analysis of magnesium segregation at a pyramidal inversion domain in a GaN epitaxial layer. Appl. Phys. Express 2019, 12, 031004. [CrossRef]

30. Hansen, M.; Chen, L.F.; Lim, S.H.; DenBaars, S.P.; Speck, J.S. Mg-rich precipitates in the p-type doping of InGaN-based laser diodes. Appl. Phys. Lett. 2002, 80, 2469-2471. [CrossRef]

31. Vennéguès, P.; Leroux, M.; Dalmasso, S.; Benaissa, M.; De Mierry, P.; Lorenzini, P.; Damilano, B.; Beaumont, B.; Massies, J.; Gibart, P. Atomic structure of pyramidal defects in Mg-doped GaN. Phys. Rev. B 2003, 68, 68. [CrossRef]

32. Reshchikov, M.A.; Yi, G.-C.; Wessels, B.W. Behavior of 2.8- and 3.2-eV photoluminescence bands in Mg-doped GaN at different temperatures and excitation densities. Phys. Rev. B 1999, 59, 13176-13183. [CrossRef]

33. Kaufmann, U.; Kunzer, M.; Maier, M.; Obloh, H.; Ramakrishnan, A.; Santic, B.; Schlotter, P. Nature of the $2.8 \mathrm{eV}$ photoluminescence band in Mg doped GaN. Appl. Phys. Lett. 1998, 72, 1326-1328. [CrossRef]

34. Kojima, K.; Takashima, S.; Edo, M.; Ueno, K.; Shimizu, M.; Takahashi, T.; Ishibashi, S.; Uedono, A.; Chichibu, S. Nitrogen vacancies as a common element of the green luminescence and nonradiative recombination centers in Mg-implanted GaN layers formed on a GaN substrate. Appl. Phys. Express 2017, 10, 061002. [CrossRef]

35. Oh, E.; Park, H.; Park, Y. Excitation density dependence of photoluminescence in GaN:Mg. Appl. Phys. Lett. 1998, 72, 70-72. [CrossRef]

36. Viswanath, A.K.; Shin, E.-J.; Lee, J.I.; Yu, S.; Kim, N.; Kim, B.; Choi, Y.; Hong, C.-H. Magnesium acceptor levels in GaN studied by photoluminescence. J. Appl. Phys. 1998, 83, 2272-2275. [CrossRef]

37. Lin, P.-J.; Tien, C.-H.; Wang, T.-Y.; Chen, C.-L.; Ou, S.-L.; Chung, B.-C.; Wuu, D.-S. On the Role of AlN Insertion Layer in Stress Control of GaN on 150-mm Si (111) Substrate. Crystals 2017, 7, 134. [CrossRef]

38. Dai, J.-J.; Liu, C.-W.; Wu, S.-K.; Huynh, S.-H.; Jiang, J.-G.; Yen, S.-A.; Mai, T.T.; Wen, H.-C.; Chou, W.-C.; Hu, C.-W.; et al. Improving

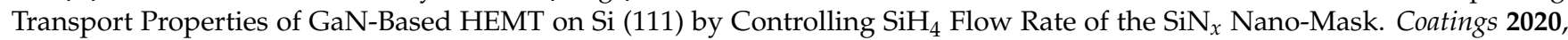
11, 16. [CrossRef]

39. Flynn, C.; Lee, W. The dependence of Raman scattering on Mg concentration in Mg-doped GaN grown by MBE. Mater. Res. Express 2014, 1, 25901. [CrossRef]

40. Kisielowski, C.; Krüger, J.; Ruvimov, S.; Suski, T.; Ager III, J.; Jones, E.; Liliental-Weber, Z.; Rubin, M.; Weber, E.; Bremser, M. Strain-related phenomena in GaN thin films. Phys. Rev. B 1996, 54, 17745. [CrossRef]

41. Ning-Yang, L.; Lei, L.; Lei, W.; Wei, Y.; Ding, L.; Lei, L.; Wen-Yu, C.; Ci-Mang, L.; Cheng-Hao, W.; Wei-Hua, C. Improvement of doping efficiency in Mg-Al0. 14Ga0. 86N/GaN superlattices with AlN interlayer by suppressing donor-like defects. Chin. Phys. B 2012, 21, 117304.

42. Wang, L.; Li, R.; Li, D.; Liu, N.; Liu, L.; Chen, W.; Wang, C.; Yang, Z.; Hu, X. Strain modulation-enhanced Mg acceptor activation efficiency of Al0.14Ga0.86N/GaN superlattices with AlN interlayer. Appl. Phys. Lett. 2010, 96, 061110. [CrossRef]

43. Lyons, J.L.; Janotti, A.; Van De Walle, C.G. Shallow versus Deep Nature of Mg Acceptors in Nitride Semiconductors. Phys. Rev. Lett. 2012, 108, 156403. [CrossRef]

44. Reddy, P.; Bryan, Z.; Bryan, I.; Kim, J.H.; Washiyama, S.; Kirste, R.; Mita, S.; Tweedie, J.; Irving, D.L.; Sitar, Z.; et al. Pinning of energy transitions of defects, complexes, and surface states in AlGaN alloys. Appl. Phys. Lett. 2020, 116, 032102. [CrossRef] 